\title{
Progesterone Concentration throughout Gestation in Cows with Singleton and Twin Pregnancies
}

\author{
Osman Valli PATEL, Toru TAKAHASHI ${ }^{1)}$, Makoto HIRAKO ${ }^{1)}$, \\ Tsuneo TOMIZUKA ${ }^{1)}$, Toshiyuki KOJIMA ${ }^{1)}$, Nobuo SASAKI and \\ Ikuo DOMEKI ${ }^{2)}$
}

Department of Veterinary Surgery and Obstetrics, Faculty of Agriculture, University of Tokyo, 1-1-1 Yayoi, Bunkyo-ku, Tokyo 113,

${ }^{1}$ Department of Animal Reproduction, National Institute of Animal Industry, P.O. Box 5, Norindanchi, Tsukuba, Ibaraki 305, and ${ }^{2}$ Department of Animal Reproduction, Faculty of Agriculture, Tokyo University of Agriculture, Sakuragaoka, Setagaya-ku, Tokyo 156, Japan

\begin{abstract}
Peripheral plasma progesterone concentrations were monitored throughout gestation in Holstein cows after non-surgical transfer of in-vitro fertilized embryos. Cows $(n=12)$ were divided into 2 groups; Group 1=single embryo, Group 2=twin embryos. To induce multiple corpora lutea prior to the embryo transfer, 3 cows in each group $(n=6)$ were randomly treated (treated cows) with either porcine follicle stimulating hormone (FSH) or pregnant mare serum gonadotropin (PMSG) followed by prostaglandin $\mathrm{F}_{2 \alpha}\left(\mathrm{PGF}_{2 \alpha}\right)$, commencing in the mid-luteal phase of the cycle preceding pregnancy. In the remaining cows $(n=6)$ estrus was synchronized by using $\mathrm{PGF}_{2 \alpha}$ (untreated cows). Treated cows had a significantly higher plasma progesterone concentration throughout gestation than untreated cows $(P<0.001)$. Treated singleton cows had higher plasma progesterone concentration in the first trimester than in the later trimesters $(P>0.05)$. Treated twin-bearing cows had a significantly higher plasma progesterone concentration in the first and the third trimester compared to the second trimester $(P<0.001)$. There was no significant $(P>0.05)$ difference in plasma progesterone concentration throughout gestation between untreated singleton and twin-bearing cows. A distinct undulation in the plasma progesterone profile was seen in all the groups between days 20 to 25 . To conclude, the plasma progesterone secretory profile was indistinguishable between untreated singleton and twin-bearing cows, and multiple corpora lutea induced by gonadotropin administration significantly boosted the progesterone pool throughout gestation.

Key words: Progesterone, Multiple-pregnancies, IVF, Cow, Embryo transfer.
\end{abstract}

(J. Reprod. Dev. 41: 63-70, 1995)

$\mathbf{P}$ rogesterone, regardless of its source, is the key hormone for maintenance of pregnancy in all mammals [1,2]. In the cow, the corpus luteum (C.L.) has been identified as the main source of

Accepted for publication: October 29, 1994

Correspondence: $N$. Sasaki progesterone in the first half of pregnancy $[3,4]$. Thereafter it is dispensible, thus lutectomy $[3,5]$ or administration of luteolytic drugs [6] between approximately 150 and 250 days of gestation does not induce abortion, indicating a possible extraovarian source of progesterone. Adrenal glands 
[5], placenta [3, 4] and progesterone sequestered in adipose tissue [7] have all been suggested to be this source of progesterone.

Present evidence suggests that the secretory products of the cow's conceptus are predominantly anti-luteolytic in nature with little or no luteotrophic effect [8] and thus progesterone concentrations throughout gestation are maintained at about mid-luteal levels. Some studies over the past three decades have attempted to characterize the progesterone secretory profiles throughout gestation in the cow with contradictory conclusions. A number of authors [9-12] found that in singleton pregnancies plasma progesterone concentration was maintained at mid-luteal levels with minimum fluctuations, while others [13, 14] reported a significant undulation in plasma progesterone concentration in singleton cows. Data on the effects of fetal number on plasma progesterone are equivocal, thus some workers [11, 15] found no difference in plasma progesterone concentration throughout gestation between cows carrying singleton and twin pregnancies, whereas others [9, 14] reported significant elevation in plasma progesterone concentration in twin carrying cows compared to singleton cows. Disagreements between the above reports could be partly attributable to infrequent and irregular blood sampling protocols. However, these studies do suggest that the peripheral plasma progesterone concentration is influenced by (i) the breed of the dam [10, 13], (ii) the number of C.L.s present $[9,14]$, (iii) fetal number $[9,14]$, and (iv) fetal sex [10].

The need for adequate progesterone during the periattachment period in the bovine is well established, with insufficient amounts frequently being blamed as a common cause of early embryonic mortality $[12,16,17]$. Moreover, the need for close synchrony of estrus in both donor and recipient cows during embryo transfer further emphasizes the critical and delicate endocrine balance during the periattachment period $[18,19]$. Attempts have been made to improve conception rates in cows either by supplementing directly with progesterone or indirectly with luteotropins in early pregnancy $[12,16,17]$.

To date, peripheral plasma progesterone profiles in gestating cows remain uncharacterized. Therefore, the objectives of this study were 2 fold, (i) to compare the plasma progesterone profiles in singleton and twin embryo recipient cows by means of frequent blood sampling throughout gestation and (ii) to elucidate the effect of multiple C.L.s induced by gonadotropins administered during the mid-luteal phase of the cycle preceding pregnancy on the subsequent progesterone profile.

\section{Materials and Methods}

\section{Animals, treatment regimen and embryo transfer}

Twelve regularly cycling Holstein cows of varying age and parity, housed and managed in the National Institute of Animal Industry, were used as recipient animals for the present study. The animals were divided into 2 equalized groups (Table 1), single embryo-recipient cows (Group 1) and twin embryo-recipient cows (Group 2). In order to induce multiple C.L.s prior to the embryo transfer 3 cows in each group were randomly assigned to one of the following treatments (treated cows), commencing in the mid-luteal phase (day 10 to 14; day 0 was defined as first day of standing estrus) of the preceding cycle, (i) cows were administered 5 to $7.5 \mathrm{mg}$ follicle stimulating hormone $(\mathrm{FSH}$, Antrin, Denka Pharmaceuticals Co., Kawasaki, Japan) once a day for 2 consecutive days and $30 \mathrm{mg}$ of prostaglandin $\mathrm{F}_{2 \alpha}\left(\mathrm{PGF}_{2 \alpha}\right.$ Panacelan, Daiichi Pharmaceutical Co., Tokyo, Japan ) in split injections 3 days later and (ii) cows were administered 2,000 I.U. of pregnant mare serum gonadotropin (PMSG, Serotropin, Teikoku Zoki Pharmaceuticals Co., Tokyo, Japan) and $30 \mathrm{mg}$ of $\mathrm{PGF}_{2 \alpha}$ in split injections 2 days later. The remaining 3 cows (untreated cows) in each group were injected with 30 $\mathrm{mg}$ of $\mathrm{PGF}_{2 \alpha}$ in split injections to synchronize estrus but no other hormonal treatment was given.

The embryos used in this study were generated by in-vitro fertilization, obtained from a commercial supplier (Tokyo Biotech. Center, Tokyo, Japan) and details of their production are given elsewhere [20]. In all cows, the embryos were non-surgically transferred on day 7 of the estrous cycle. A singleton pregnancy was established by transfer of a single embryo into the uterine horn ipsilateral to the corpus-luteum bearing ovary. A twin pregnancy was established by transfer of individual embryos into each uterine horn. Preceding embryo transfer (E.T.), the number of C.L.s and other ovarian features were evaluated by transrectal ultrasonography (Aloka 650, Aloka Co., Tokyo, Japan) and recorded. Pregnancy was confirmed at 
day 30 by ultrasonography.

\section{Blood collection}

Blood was collected via jugular venipuncture into a $50 \mathrm{ml}$ heparinized polypropylene tube, placed immediately on ice and centrifuged $(3,000 \mathrm{rpm}$ at $4 \mathrm{C}$ for $1 \mathrm{~h}$ ) within $1 \mathrm{~h}$ of collection. The harvested plasma was stored at $-20 \mathrm{C}$ until assayed. Blood was collected about every third day from day 0 , then daily for the last 10 days of gestation and sampling was stopped a day after parturition.

\section{Sample extraction and radioimmunoassay}

The method used in this study for extraction of plasma progesterone was slightly modified from that described elsewhere [21]. Briefly, $100 \mu \mathrm{l}$ of distilled water was added to duplicate aliquots of sample $(20 \mu \mathrm{l})$ prior to diethyl ether extraction (Wako Pure Chemicals Co., Osaka, Japan). Each sample was extracted by vortex mixing for approximately $5 \mathrm{~min}$ with $2 \mathrm{ml}$ of diethyl ether. After separation of the 2 phases, the aqueous phase was snap frozen by immersion in a cold ethanol bath. The organic layer was decanted into glass test tubes and evaporated under nitrogen gas. The dried sam- ple residues were dissolved in $200 \mu$ l of assay buffer [0.01 M phosphate buffered saline containing 1\% bovine serum albumin (Sigma Chemicals Co., St. Louis, USA), pH 7.1]. The recovery of progesterone by this method was $99 \%$. Thereafter, $200 \mu \mathrm{l}$ of antibody at a dilution of 1:400,000 (anti-P-3-CMOBSA, Teikoku Zoki Pharmaceuticals Co., Tokyo, Japan) was added to the extracted samples and to triplicate aliquots of appropriately diluted working standards and left overnight at $4 \mathrm{C}$. The following morning, $100 \mu \mathrm{l}$ of tritiated progesterone $(1,2,6,7,21-3 \mathrm{H}-\mathrm{P}$, New England Nuclear, Boston, USA) approximately 10,000 cpm was added to all tubes and they were further incubated for $24 \mathrm{~h}$ at $4 \mathrm{C}$. Free and bound hormone was separated by centrifugation $(3,000 \mathrm{rpm}$ at $4 \mathrm{C}$ for 20 min) after addition of $500 \mu \mathrm{l}$ of dextran-coated charcoal (Norit A, Wako Pure Chemicals Co., Osaka, Japan). Thereafter, $600 \mu \mathrm{l}$ of the supernatant was aspirated into scintillation vials containing toluene based scintillant (Dojindo Laboratories, Kumamoto, Japan). Assay sensitivity was $<0.5 \mathrm{ng} / \mathrm{ml}$ and intra- and inter-assay coefficients of variation were 7 and $11 \%$, respectively.

Table 1. Cow allotment and gestational data

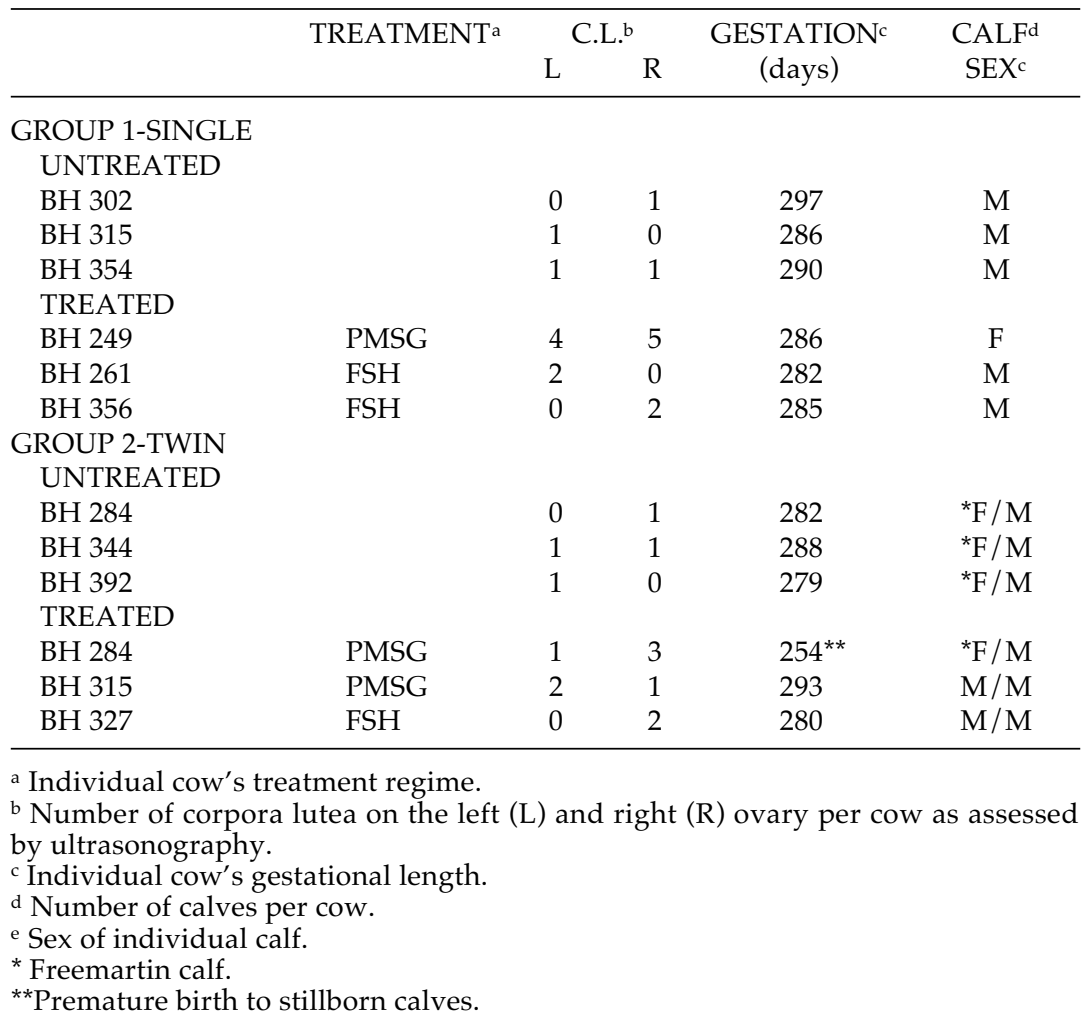




\section{Statistical analysis}

Differences in plasma progesterone concentration within trimesters in a group and between groups were subjected to split-plot ANOVA and analyzed by the general linear models (GLM) procedure of SAS [22]. Single point means were compared by Student's $t$-test. The relationships between the C.L. number and the progesterone concentration were analyzed by Pearson's method [22]. The hormone data were approximated to the nearest fifth day of gestation in each cow prior to the analysis.

\section{Results}

The number of C.L.s per cow, each cow's gestational length, fetal number per cow and sex of each fetus are shown in Table 1. The mean plasma
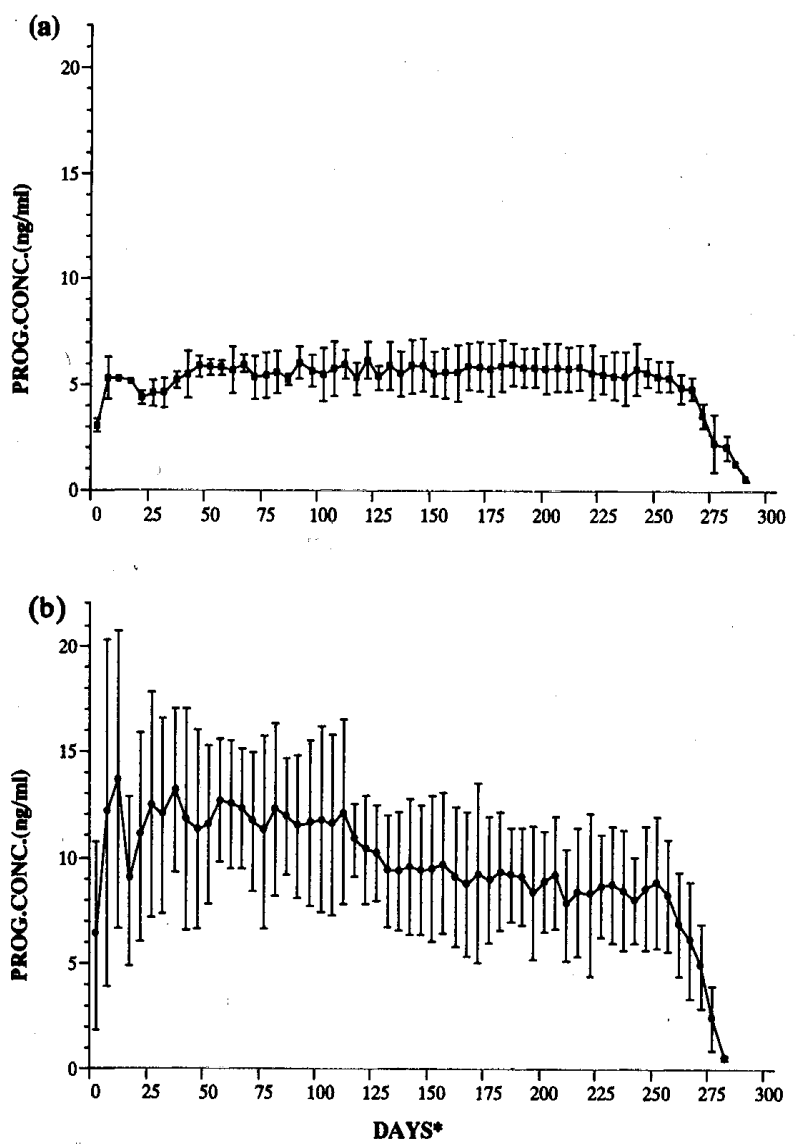

Fig. 1. Mean ( \pm S.D.) plasma progesterone concentration thoughout gestation in (a) untreated and (b) treated singleton cows. *Day $0=$ day of E.T. progesterone concentration remained elevated throughout gestation in all the cows as shown in Figs. 1 and 2. The plasma progesterone concentration was significantly correlated to the number of C.L.s in the treated $(\mathrm{P}<0.0001)$ and untreated $(\mathrm{P}<0.001)$ cows throughout gestation as shown in Table 2. The mean gestation length was shorter $(\mathrm{P}>0.05)$ in the twin-bearing cows compared to singleton cows $(279.3 \pm 12.3$ vs $287.6 \pm 4.7$, respectively).

Plasma progesterone concentration throughout gestation in untreated singleton and twin-bearing cows

The mean number of C.L.s $(1.3 \pm 0.6$ vs $1.3 \pm 0.6)$ was identical in the 2 groups and there was also no significant difference $(\mathrm{P}>0.05)$ in the mean plasma progesterone concentration between the 2 groups throughout the gestation period, as shown in Figs. $1 \mathrm{a}$ and $2 \mathrm{a}$, respectively. A significant
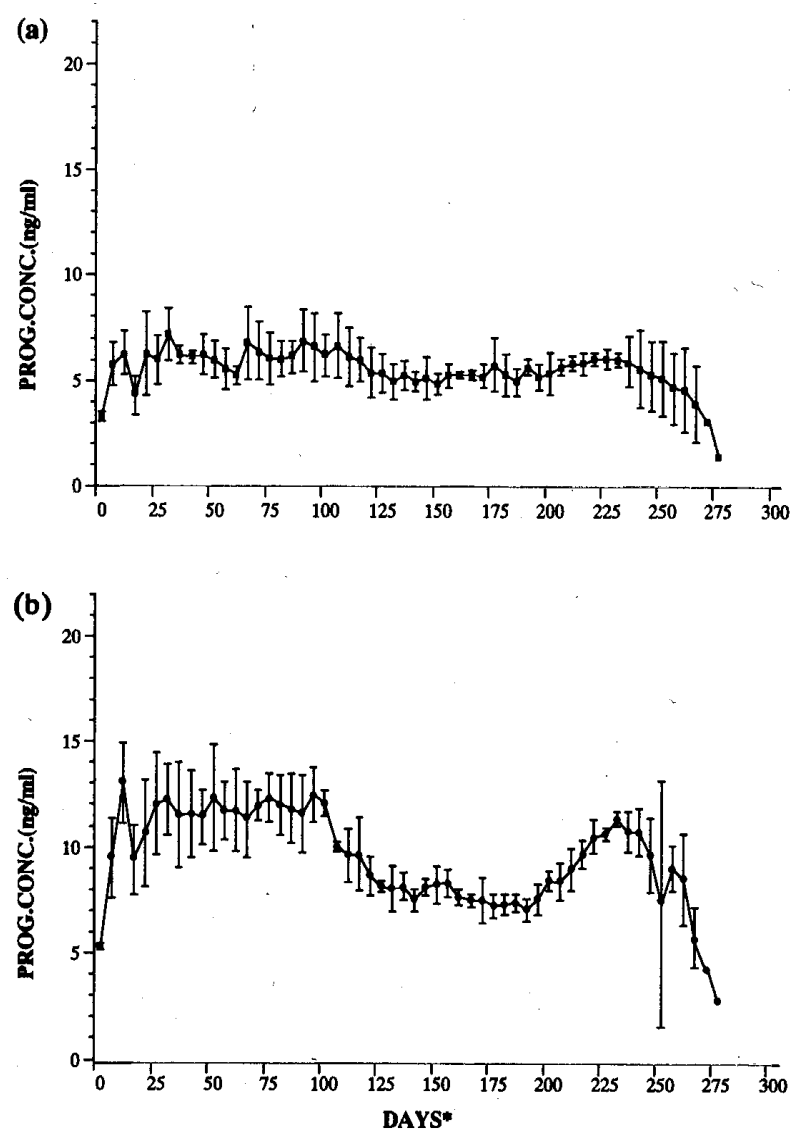

Fig. 2. Mean ( \pm S.D.) plasma progesterone concentration thoughout gestation in (a) untreated and (b) treated twin-bearing cows. *Day $0=$ day of E.T. 
Table 2. Correlation coefficient (r) between C.L. number and progesterone concentration throughout gestation in untreated and treated cows

\begin{tabular}{lccc}
\hline & $\begin{array}{c}\text { First } \\
\text { trimester }\end{array}$ & $\begin{array}{c}\text { Second } \\
\text { trimester }\end{array}$ & $\begin{array}{c}\text { Third } \\
\text { trimester }\end{array}$ \\
\hline untreated & $0.34^{* *}$ & $0.34^{* *}$ & $0.34^{* *}$ \\
treated & $0.86^{* * *}$ & $0.89^{* * *}$ & $0.64^{* * *}$ \\
\hline
\end{tabular}

${ }^{* *} \mathrm{P}<0.001,{ }^{* * *} \mathrm{P}<0.0001$

$(\mathrm{P}<0.01)$ transient decline in the mean plasma progesterone concentration was observed around day 25 in singleton cows and around day 20 in the twin-bearing cows. Thereafter, the mean plasma progesterone concentration in both groups remained elevated up to approximately day 265 but the profile was more undulating in twin-bearing cows compared to singleton cows. In cows of both groups the mean plasma progesterone concentration declined rapidly as parturition approached and reached a concentration of $<1 \mathrm{ng} / \mathrm{ml}$ on the day of parturition.

\section{Plasma progesterone concentration throughout gestation in treated singleton and twin-bearing cows}

The mean number of C.L.s $(\mathrm{P}>0.05)$ was higher $(4.3 \pm 3.1$ vs $3.0 \pm 1.0)$ and also the variation between individuals was markedly larger in singleton cows than in twin-bearing cows. Singleton cows had a higher $(\mathrm{P}>0.05)$ plasma progesterone concentration in the first trimester than in the later trimesters. Twin-bearing cows had a significantly $(\mathrm{P}<0.001)$ higher plasma progesterone concentration in the first and the third trimesters compared to the second trimester. On the other hand, there was no significant $(\mathrm{P}>0.05)$ difference in the mean plasma progesterone concentration between the two groups throughout the gestation period, as shown in Figs. $1 b$ and $2 b$, respectively. A transitory decline in the mean plasma progesterone concentration was observed around day 20 that was marked in singleton $(P>0.05)$ cows but significant in twin-bearing $(\mathrm{P}<0.05)$ cows. Thereafter, the mean plasma progesterone concentration remained elevated up to about day 100 and subsequently declined in singleton $(\mathrm{P}>0.05)$ and in twin-bearing cows $(\mathrm{P}<0.001)$. In the twin-bearing cows the mean concentration stabilized at this decreased level up to about day 200 and subsequently it gradually but significantly $(\mathrm{P}<0.001)$ increased to peak at about day 225 at similar levels as in early gestation. In cows of both groups the mean plasma progesterone concentration declined rapidly from about day 260 to reach a concentration of $<1 \mathrm{ng} /$ $\mathrm{ml}$ on the day of parturition. The large standard deviation (S.D.) bar around day 250 in the twinbearing cows was due to one of the cows giving birth prematurely to stillborn calves.

Plasma progesterone concentration throughout gestation in untreated and treated singleton cows

The mean number of C.L.s was significantly $(\mathrm{P}<0.01)$ larger in the treated than in the untreated group ( $4.3 \pm 3.1$ vs $1.3 \pm 0.6)$. The mean plasma progesterone concentration throughout the gestation period was also significantly $(\mathrm{P}<0.001)$ higher in the treated group than in the untreated group, as shown in Fig. 1. The difference between the concentration on the day of E.T. and the peak concentration plus the transient decrease in early gestation were $(P>0.05)$ larger in the treated cows compared to the untreated cows. The mean concentration after the decreasing phase increased gradually in the untreated group but rapidly in the treated group to peak levels. On the other hand, the decrease seen in the mean concentration of the treated group $(P>0.05)$ at about day 100 was not evident in the untreated group. In both groups the mean concentration declined rapidly as parturition approached.

\section{Plasma progesterone concentration throughout gestation in untreated and treated twin-bearing cows}

The mean number of C.L.s was larger $(\mathrm{P}>0.05)$ in the treated than in the untreated group $(3.0 \pm$ 1.0 vs $1.3 \pm 0.6$ ). The mean plasma progesterone concentration throughout gestation was significantly $(\mathrm{P}<0.001)$ higher in the treated than in the untreated group, as shown in Fig. 2. The increase in concentration from the day of E.T. to the peak concentration and transient decrease in early gestation were significantly $(\mathrm{P}<0.001)$ larger in the treated cows than in the untreated cows. A trend $(P>0.05)$ similar to that of significant $(P<0.001)$ undulations seen in the treated cows around day 100 and 200 was also evident in the untreated cows at about the same time. The mean plasma concentration declined rapidly in both groups as parturition approached. 


\section{Discussion}

In general the plasma progesterone secretory profile of untreated singleton cows reported here is consistent with that of several other authors [9$11,15]$ but different from that reported elsewhere $[13,14]$. In addition, the result that there was no significant difference between the profiles of untreated singleton and twin-bearing cows is in agreement with some earlier reports [11, 15] but contradictory to others $[9,14]$. Reduced gestational length in twin-bearing cows and also the significantly elevated progesterone concentration found throughout the gestation period in treated cows are comparable with earlier investigations [9, 14].

It is interesting to note that none of the earlier studies reported the distinct undulation between days 20 to 25 in the progesterone profiles observed in all four groups in our study. Their failure to detect this significant variation could be directly related to their infrequent and irregular blood sampling protocols. In a different study, the decreasing and increasing phases with daily sampling were shown to be more gradual than in the present study and that the decreasing phase commenced as early as day 17 [23]. In the present study, the amplitude of the increasing and the decreasing phases was apparently related to the number of C.L.s present (Figs. 1 and 2). Ultrasonography in pregnant cows revealed fluctuations in the area, height and width of the C.L., especially after day 15 [23, 24]. In addition, Lukaszewska and Hansel [25] found no difference in plasma $\mathrm{PGF}_{2 \alpha}$ concentration in pregnant and non-pregnant cows at day 18. Thus it seems possible that the $\mathrm{PGF}_{2 \alpha}$ secreted from the uterus at this early stage of pregnancy causes some alterations in the secretory activity of the luteal cells and reduces steroidogenesis but this effect is counteracted by secretory products from the conceptus [8] and progesterone production is normalized.

Growth rates of embryos fertilized in vitro are known to be reduced compared to natural embryos $[26,27]$. It is possible that due to this retardation the embryo elicits inadequate signals to prevent the onset of luteolysis, and as a result low pregnancy rates are recorded [27]. Some workers have advocated a plasma progesterone level of more than $3 \mathrm{ng} / \mathrm{ml}$ on the day of E.T. for successful conception to take place $[16,21]$. Consequently, prior supplementation with progesterone is known to improve conception rates [15-17]. In our study, the mean plasma progesterone concentration throughout gestation was $>3 \mathrm{ng} / \mathrm{ml}$ in the treated cows. Interestingly, our method of inducing multiple C.L.s before E.T. boosts plasma progesterone pool throughout gestation (Figs. $1 \mathrm{~b}$ and $2 \mathrm{~b}$ ) as opposed to the transitory elevation with progesterone supplemental method [15, 17]. Our method further reduces the laborious need of frequent injections and stress added to the animals. On the other hand, even with the low doses of gonadotropins used in the present study, results of marked variation in PMSG treated cows and consistent response in FSH treated cows (Table 1) are comparable to earlier studies employing recommended doses [28, 29].

Shemesh [4] reported that the placenta was capable of synthesizing significant amounts of progesterone from about day 90 onwards from which time it also releases an inhibitory factor(s) which reduces luteal steroidogenesis [30]. On the other hand, luteinizing hormone (LH) is believed to be the major luteotropin in cattle and progesterone is known to modulate LH pulse frequency [31]. In addition, LH pulse amplitude and frequency is greater in early gestation than that observed during mid-gestation [32]. Thus a combination of reduced LH support and concomitant release of a placental inhibitor may be responsible for the low mean plasma progesterone concentration seen around day 100 (Figs. $1 b$ and $2 b$ ). Furthermore, our results indicate that the inhibitory effect of the placenta is significantly augmented by the number of C.L.s present.

Extra-ovarian source(s) in the cow secrete adequate progesterone in late gestation to sustain pregnancy $[4,5]$ but ovariectomy or lutectomy during this period decreases the maternal peripheral plasma progesterone concentration to low levels $[3,5]$, indicating that the C.L. is the principal source of the peripheral progesterone throughout gestation. Furthermore, the weight of the C.L. in the cow remains consistent throughout gestation and equally responsive to luteotrophic stimuli [33]. Although we did not sequentially monitor the C.L.s throughout gestation, it was probably the prime source of the peripheral progesterone in the present study as substantiated by the correlation results (Table 2). Notwithstanding, in the rhesus mon- 
key, there is evidence that the fetus does regulate the extra-ovarian progesterone production and that the genotype significantly influences it [34]. In addition, in the same species the C.L.'s secretory activity is enhanced in late gestation when monkey chorionic gonadotropin (mCG) is undetectable in the peripheral plasma [35]. However, it still remains to be verified how these observations can be extrapolated to other species, as there is a reduction in the peripheral LH in late gestation in the cow [32] but fetectomy has no significant effect on maternal plasma progesterone levels [7] and so far data on the effect of fetal sex in this species are conflicting $[10,36]$. Other luteotrophic factors have been identified in the cow but their in vivo effect has yet to be clearly delineated $[37,38]$. Accordingly, the undulations in the progesterone profile in late gestation of the twin-bearing cows suggest that unidentified trophic factor(s) of fetal and/or placental origin regulate luteal steroidogenesis during this period, with its (their) cumulative effect being dependent on both the number of C.L.s and feti present, but these factors needs further verification.

To conclude, plasma progesterone secretory profiles were indistinguishable between untreated singleton and twin-bearing cows, and multiple C.L.s induced by gonadotropin administration significantly boosted the peripheral plasma progesterone pool throughout gestation. Further- more, our results do demonstrate that the progesterone concentration throughout gestation is significantly correlated to the number of C.L.s present and that regulation of its secretion throughout gestation is complex, probably involving an intricate interaction between the dam, the fetus and the placenta. However, further work is needed to confirm and clarify this.

\section{Acknowledgments}

We thank N. Takenouchi, Chugoku National Agricultural Experiment Station, K. Iwama, Kyoritsu Shoji Co., Ltd., M. Kobayashi, Morinaga Milk Industry Co., Ltd., N. Kusakari, Takikawa Animal Husbandry Experimental Station and T. Iwahori, Shizuoka Prefectual Animal Husbandry Experiment Station for their assistance with sample collection. A. Kambegawa of Teikoku-zoki Pharmaceutical Co., Ltd., for the gift of progesterone anti-sera. M. Takahashi of National Institute of Animal Industry for graphical assistance and $\mathrm{H}$. Kamomae of Tokyo University of Agriculture and Technology for valuable advice. We also express our gratitude to Dr I. A. Jeffcoate of the University of Glasgow Veterinary School for critically reading the manuscript. O. V. Patel is currently on a Ph.D fellowship from the Japanese Ministry of Education (Monbusho).

\section{References}

1. Heap RB. Role of hormones in pregnancy. In: Austin CR, Short RV (eds.), Reproduction in Mammals, Book 3: Hormones in Reproduction. Cambridge Univ. Press, Cambridge, 1972; 73-105.

2. Levasseur M. Utero-ovarian relationships in placental mammals: role of uterus and embryo in regulation of progesterone secretion by the corpus luteum. A review. Reprod Nutr Dev 1983; 23: 793816.

3. Pimental SM, Pimental CA, Weston PG, Hixon JE. Progesterone secretion by the bovine fetoplacental unit and responsiveness of corpora lutea to steroidogenic stimuli at two stages of gestation. Am J Vet Res 1986; 47: 1967-1971.

4. Shemesh M. Production and regulation of progestrone in the bovine corpus luteum and placenta in mid and late gestation: a personnel view. Reprod Fert Dev 1990; 2: 129-135.

5. Wendorf GL, Lawyer MS, First NL. Role of adrenals in the maintenance of pregnancy in cows. J Reprod Fert 1983; 68: 281-287.

6. Johnson WH, Manns JG, Adams WM. Termination of pregnancy with cloprostenol and dexamethasone in intact or ovariectomized cows. Can Vet J 1981; 22: 288-290.

7. Hoffman B, Wagner WC, Hixon JE, Bahr J. Observations concerning the functional status of the corpus luteum and placenta around parturition in the cow. Anim Reprod Sci 1979; 2: 253-266.

8. Bazer FW, Troy LO, Spencer TE. Pregnancy recognition in ruminants, pigs and horses: signals from the trophoblast. Theriogenology 1994; 41: 79-94.

9. Adelakoun V, Matton P, Dufour JJ. Steroid hormone levels in beef cows during pregnancy terminating in normal calving or abortion and with single or multiple ovulation. Can J Anim Sci 1978; 58: 345-354.

10. Agarwal SP, Agarwal VK, Ahmad A. Studies on 
steroid hormones. 3. Serum progesterone concentration in zebu cows during pregnancy. Indian J Anim Sci 1980; 50: 706-709.

11. Dobson H, Rowan TG, Kippax SI, Humblot P. Assessment of fetal number, and fetal and placental viability throughout pregnancy in cattle. Theriogenology 1993; 40: 411-425.

12. Sreenan JM, Diskin MG, Murphy M. Fertilization and embryo survival rates in control and progesterone or HCG treated heifers. Ann Biol Anim Biochem Biophy 1979; 19: 1619.

13. Mugerwa EM, Tegegne A. Peripheral plasma progesterone concentration in zebu cows during pregnancy. Reprod Nutr Dev 1989; 29: 303-308.

14. Echternkamp SE. Fetal development in cattle with mutiple ovulations. J Anim Sci 1992; 70: 2309-2321.

15. Sreenan JM, Gesling JP, Terqui M, Thimonier J. Diagnosis of twin pregnancy and subsequent calving results following bilateral egg transfer in beef heifers. Theriogenology 1978; 9:103 (Abstract).

16. Sreenan JM, Diskin MG. Early embryonic mortality in the cow: Its relationship with progesterone concentration. Vet Rec 1983; 112: 517-521.

17. Robinson NA, Leslie KE, Walton JS. Effect of treatment with progesterone on pregnancy rates and plasma concentrations of progesterone in Holstein cows. J Dairy Sci 1989; 72: 202-207.

18. Rowson LEA, Lawson RAS, Moor RM, Baker AA. Egg transfer in the cow: synchronization requirements. J Reprod Fert 1972; 28: 427-431.

19. Maurer RR, Ecternkamp SE. Hormonal asynchrony and embryonic development. Theriogenology 1982; 17: 11-22.

20. Kuwayama M, Hamano S, Nagai T. Vitrification of bovine blastocysts obtained by in vitro culture of oocytes matured and fertilized in vitro. J Reprod Fert 1992; 96: 187-193.

21. Goto K, Nakanishi Y, Ohkutsu S, Ogawa K, Tasaki M, Ohta $H$, Inohae S, Tateyama S, Kawabata T. Plasma progesterone profile and embryo quality in superovulated Japanese Black cattle. Theriogenology 1987; 27: 819-826.

22. SAS ${ }^{\circledR}$ User's Guide: Statistics, Version 6.03 Edition. 1988. SAS Inst., Inc., Cary, NC.

23. Patel OV. An investigation of a repeat breeder problem in dairy cows. 1990; Masters Thesis, Glasgow University.

24. Kastelic JP, Bergfelt DR, Ginther OJ. Relationship between ultrasonic assessment of the corpus luteum and plasma progesterone concentration in heifers. Theriogenology 1990; 33: 1269-1278.

25. Lukaszewska J, Hansel W. Corpus luteum main- tenance in early pregnancy in cow. J Reprod Fert 1980; 59: 485-493.

26. Xu KP, Greve T, Callesen H, Hyttel P. Pregnancy resulting from cattle oocytes matured and fertilized in vitro. J Reprod Fert 1987; 81: 501-504.

27. Iwasaki S. Studies on cytogenetics and morphological assessment of bovine embryos fertilized in vitro. J Reprod Dev 1992; 38: 109-119 (In Japanese with English summary).

28. Seidel GE, Elsden RP, Nelson LD, Bowen RA. Superovulation of cattle with pregnant mare's serum gonadotropin and follicle stimulating hormone. In: Sreenen JM(ed), Control of Reproduction in the Cow. Martinus Nijhoff, Hague 1978; 159-168.

29. Yadav MC, Walton JS, Leslie KE. Plasma concentrations of luteinizing hormone and progesterone during superovulation of dairy cows using follicle stimulating hormone or pregnant mare serum gonadotropin. Theriogenology 1986; 26: 523-526.

30. Shemesh M, Hansel W, Strauss JF. Bovine placentomes contains factors which decrease progesterone secretion. Biol Reprod 1983; 29: 856862.

31. Goodman RL, Karsch FJ. Pulsatile secretion of luteinizing hormone: differential suppression by ovarian steroids. Endocrinology 1980; 107: 12861290.

32. Schallenberger E, Rampp J, Walters DL. Gonadotrophins and ovarian steroids in cattle. (II) Pulsatile changes of concentrations in the jugular vein throughout pregnancy. Acta Endocrinol 1985; 108: 322-330.

33. Mills RC, Morrissette MC. Progesterone synthesis by perfused bovine ovaries of early and late gestation. J Reprod Fert 1970; 22: 435-440.

34. Hagemenas FC, Baughman WL, Kittinger GW. The effect of foetal hypophysectomy on placental biosynthesis of progesterone in rhesus. Endocrinology 1975; 96: 1059-1062.

35. Scholl SA, Wolf RC. Quantification of a 20 alpha and 20 beta-dihydrogenase in plasma of the pregnant rhesus monkey. Steroids 1974; 23; 269-289.

36. Echternkamp SE. Relationship between placental development and calf birth weight in beef cattle. Anim Reprod Sci 1993; 32: 1-13.

37. Hansel W. Plasma hormone concentrations associated with early embryo mortality in heifers. J Reprod Fert 1981; Suppl 30: 231-239.

38. Ailenberg M, Shemesh M. Partial purification of a chorionic gonadotropin-like protein from bovine cotyledons. Biol Reprod 1983; 28: 517-522. 